\title{
Longitudinal study of rural health workforce in five counties in China: research design and baseline description
}

Huiwen Xu', Weijun Zhang ${ }^{\dagger}$, Xiulan Zhang, Zhiyong Qu, Xiaohua Wang, Zhihong Sa, Yafang Li, Shuliang Zhao, Xuan Qi and Donghua Tian*

\begin{abstract}
Background: The village doctors have served rural residents for many decades in China, and their role in rural health system has been highly praised in the world; unfortunately, less attention has been paid to the health workforce during the ambitious healthcare reform in recent years. Therefore, we conducted a longitudinal study to explore the current situation and track the future evolution of the rural healthcare workforce.

Methods: The self-administered structured Village Clinic Questionnaire and Village Doctor Questionnaire, which were modified from the official questionnaires of the Ministry of Health, were constructed after three focus groups, in-depth interviews in Hebei Province, and a pilot survey in Sichuan Province. Using a stratified multistage cluster sampling process, we gathered baseline data for a longitudinal survey of village doctors, village clinics from Changshu County, Liyang County, Yongchuan District, Mianzhu County, and Jingning County in China in 2011. Well-trained interviewers and strict procedures were employed to ensure the quality of this survey. Descriptive and correlation analyses were performed with Stata 12.0.
\end{abstract}

Results: After four months of surveying, 1,982 Village Doctor Questionnaires were collected, and the response rate was $88.1 \%$. There were 1,507 (76.0\%) male and 475 (24.0\%) female doctors, with an average age of 51.3 years. The majority of village doctors (58.5\%) practiced both western medicine and Traditional Chinese Medicine, and 91.2\% of the doctors received their education below college level. Their practice methods were not correlated with education level $(P=0.43)$, but closely related to the way they obtained their highest degree (that is, prior to starting work or as on-the-job training) $(P<0.01)$. The mean income of the village doctors was $1,817(95 \% \mathrm{Cl}$ $1,733$ to 1,900$)$ RMB per month in 2011; only 757 (41.3\%) doctors had pensions, and the self-reported expected pension was 1,965 RMB per month.

Conclusions: Village doctors in rural China are facing critical challenges, including aging, gender imbalance, low education, and a lack of social protection. This study may be beneficial for making better policies for the development of the health workforce and China's healthcare reform.

Keywords: Rural health workforce, Human resources for health, Village doctors, Barefoot doctors, China

\footnotetext{
* Correspondence: tian65216@hotmail.com

'Equal contributors

China Institute of Health, School of Social Development and Public Policy, Beijing Normal University, 19 Xinjiekou Wai Street, Haidian District, Beijing, 100875, China
}

\section{Biomed Central}

(c) 2013 Xu et al.; licensee BioMed Central Ltd. This is an Open Access article distributed under the terms of the Creative Commons Attribution License (http://creativecommons.org/licenses/by/2.0), which permits unrestricted use, distribution, and reproduction in any medium, provided the original work is properly cited. 


\section{Background}

China has undergone ambitious and systematic healthcare reform since the central government established a series of healthcare policies in 2009 [1] to meet the demands of its 1.3 billion citizens for an equitable, affordable, and efficient healthcare system. The reform efforts over the previous 3 years have put priorities on the financing of public health and primary health care, the subsidization of universal health insurance coverage, the establishment of National Essential Drugs List, and public hospital reform [2]. These issues are closely related to the human resources for health, and the new policies affect medical service practice, productivity, and time allocation for public health and clinical service. For example, public health programs have been launched, and the numbers of patients seeking medical service have greatly increased due to the ongoing universal health coverage. On the other hand, the healthcare workers will also influence the progress and implementation of the reforms [3], and the shortage and misdistribution of healthcare workforces are major obstacles to strengthening the public healthcare and the primary health care system and to achieving the policy goals of health care reform [2]. Therefore, more attention should be paid to the development of the healthcare workforce [4], especially in rural areas, where the human resources are typically underprovided in both quantity and quality because of low salary, uncomfortable work environment, and poor education for young children [5-7].

In regard to the healthcare workforce in China, the most well-known and widely discussed issue might be the barefoot doctors in rural China [8-13], which has served as an example of solving shortages of medical services in rural areas [14]. In 1968, the barefoot doctors program became a national policy and obtained high political priority in order to solve the substantial shortage of healthcare workers in rural China [15]. At the same time, the quantity of barefoot doctors increased dramatically as they were allowed to provide medical services after a short period of training at a county or community hospital [14]. By the 1970s, there were approximately 5 million rural healthcare workers, including 1.8 million barefoot doctors, 3.5 million hygienists, and 0.7 million midwives [16]. During that time, immunization, maternal health care, and other public health services, together with medical services were delivered by barefoot doctors [14]. Most barefoot doctors practiced a mixture of basic western medicine and Traditional Chinese Medicine (TCM). Barefoot doctors, together with the Cooperative Medical Scheme, which covered the cost of medical services, ensured the success in the prevention of communicable diseases, reduced the infant mortality rate, and lengthened life expectancy in rural areas of China [17].
Since the 1980s, China has undergone a large and complex economic and social transition [18-22], and the collective economy and Cooperative Medical Scheme collapsed in rural China, which resulted in a decrease in numbers of barefoot doctors [14]. Concurrently, the Ministry of Health $(\mathrm{MOH})$ started to streamline the numbers of barefoot doctors and to improve their quality [16], and in 1985 the title 'barefoot doctor' was abandoned; about 0.64 million doctors who passed the qualifying examination obtained a certificate as a village doctor $[14,23]$.

To further improve the quality of village doctors, the central government published a series of policies beginning in the 1990s. In 1991, the MOH released the '19912000 National Education Plan of Village Doctors', which required $80 \%$ of village doctors to reach the requirements of Systematization and Normalization. In 2002, the '2001-2015 Health Workforce Development Outlines' were published with specific goals: village doctors should obtain an education degree of secondary school or above, and $85 \%$ of village doctors should pass the exam and get the assistant doctor license by the end of 2015. The 'Village Doctors Practitioners Regulation' was released by the State Council in 2003, which particularly regulated the certification, practice, training and legal obligations of village doctors, establishing the first set of national regulations for village doctors. After the regulations were published, the number of village doctors quickly decreased to 0.8 million in 2003 [24]. As a result of the New Cooperative Medical Scheme, which was introduced in 2003 and continued the economic growth that began in the 1980s, the healthcare demands of rural residents dramatically increased. The number of healthcare workers in rural areas was subsequently increased, including 1 million village doctors and 65,895 hygienists, and there were about 1.3 rural healthcare workers (both village doctors and hygienists) per 1000 rural residents at the end of the year 2011 [24].

Although several national policies were established for village doctors, there were no special guidelines regarding their income or pension. In fact, since 1985, the village doctors have become private, for-profit practitioners [14], and most of their income was derived from their medical practice and nothing was derived from public health service. However, such situations have been changed since the healthcare reform began. In the reformed health system, village doctors have been required to deliver both public health and primary medical services to rural residents, and the Essential Drugs List was conducted in the village clinics, which required the village doctors to provide drugs with zero-profit [2]. To compensate the potential income loss of village doctors, the central government established three refund channels: the public health subsidies, the Essential Drugs List allowance, and a 
general outpatient fee. Hence, the new policy inevitably led to medical service behavior changes of village doctors. However, the outcome of the new policy is still unclear.

The studies on barefoot doctors began showing up in 1972 when there were several articles that introduced the development, training, payment, and job satisfaction of barefoot doctors [9,11-13,25]. Several other studies discussed the potential problems of barefoot doctors including decentralized training, low quality, job dissatisfaction [26], number, age, workload and income of village doctors [27,28], and even suggested the possibility of exporting the concept of barefoot doctors to other countries [29]. After the collapse of the collective economy and following the economic reform, the transition and training mechanisms of village doctors were studied [21,30,31], and the recent studies investigated the evolution $[14,16]$ and the prescribing behavior of village doctors [32].

However, there are problems among these studies. Most of the studies were conducted decades ago, and as a result of the substantial social and economical changes in recent years, these studies do not describe the current status of village doctors; nor do most of these studies contain detailed data describing the characteristics of village doctors. Furthermore, the annual organizationbased administrative survey conducted by the $\mathrm{MOH}$ only covers health institutions at the township level and above, and lack comprehensive information about village doctors [23,33].

Because the village doctors act as gatekeepers for the rural residents [24], they are likely to have a profound impact on China's healthcare system and on the health status of rural residents. Consequently, we conducted a longitudinal study of rural health workforce project in China to identify the basic demographic characteristics (for example, age, sex, and education) and current situations (for example, income and training) of these healthcare workers and to track their future trends, particularly the impacts of healthcare reform on the village doctors. For further understanding of the healthcare workforce in rural areas, healthcare workers in township health centers (THCs) were also investigated. This study primarily focuses on the research design, including questionnaire construction, sampling procedure, data collection and statistical analysis; and the baseline characteristics of village doctors.

\section{Methods}

The Rural Health Workforce Project in China is a longitudinal nationwide study conducted by the China Institute of Health projected from year 2011 to 2020, and three waves of data are expected to be collected in 2011, 2015, and 2020. The baseline data (first wave) were gathered from July to November in 2011.

\section{Questionnaires}

China has its own organization-based annual survey on healthcare institutions, but this survey primarily focuses on townships and above, and does not cover the individual data regarding rural healthcare workers [24,33]. Based on the official questionnaires from the $\mathrm{MOH}$, and after adding detailed individual information, personal history and attitude changes after the healthcare reform to the questionnaires, we constructed a self-administered, structured Village Clinic Questionnaire and a Village Doctor Questionnaire.

After the initial version of the questionnaires were determined, we performed in-depth interviews with the local health administrators, directors and healthcare workers of the THCs and the village doctors in Xiong County, Hebei Province, in February 2011. We held three focus groups that included sociologists, physicians, statisticians, economists, health policy researchers, and administrators from the $\mathrm{MOH}$ to discuss the structure and contents of the questionnaires, and we undertook a major revision in May 2011 after convening the focus groups. In July 2011, a pilot survey was conducted in Mianzhu County, Sichuan Province, and 40 village doctors, 10 doctors from 3 THCs were interviewed with the questionnaires by the interviewers from the China Institute of Health. We then modified some questions that did not meet our needs, and developed the final version of the questionnaires.

The Village Doctor Questionnaire was divided into five parts: the basic information (age, gender, year started working as a village doctor, education, the manner of obtaining their highest degree of certification, and whether or not the doctor served as a director of a village clinic); primary healthcare services, public health services, charges of per visit (including common acute diseases and chronic diseases); the knowledge of hypertension and diabetes; the treatment of village doctors (for example, basic medical income, change of income after health reform, pension); and the training (including time, place, institute, contents and self-assessment of required training). The options provided for basic information were consistent with the official statistics to ensure a comparison between the data from the China Health Statistics Yearbook and other official statistics data.

\section{Sampling}

A multistage cluster sampling method was used in this study. At the first stage, we selected Jiangsu Province (southeast), Sichuan Province (southwest), Chongqing Municipality (middle-west), and Gansu Province (northwest) from the 34 provinces or municipalities of China; then we chose a county or district from each province or municipality: Changshu County from Jiangsu; Mianzhu 
Table 1 The basic characteristics of the sampling counties

\begin{tabular}{lcccccc}
\hline County & $\begin{array}{c}\text { GDP per capita } \\
\text { (RMB) }\end{array}$ & $\begin{array}{c}\text { Financial expenditure } \\
\text { (100 million RMB) }\end{array}$ & $\begin{array}{c}\text { Population } \\
\text { (10 thousand) }\end{array}$ & $\begin{array}{c}\text { Rural } \\
\text { residents (\%) }\end{array}$ & $\begin{array}{c}\text { Hospital beds } \\
\text { (per 1000 capita) }\end{array}$ & $\begin{array}{c}\text { Doctors } \\
\text { (per 1000 capita) }\end{array}$ \\
\hline${\text { Changshu }{ }^{a} \text { [34] }}^{\text {(10) }}$ & $96,518.0$ & 95.4 & 106.7 & 20.2 & 4.6 & 2.3 \\
Liyang $^{\mathrm{a}}$ [34] & $56,784.0$ & 33.5 & 78.2 & 19.8 & 2.9 & 1.6 \\
Mianzhu [35] & $24,533.0$ & 5.9 & 51.3 & 74.3 & 4.9 & 1.4 \\
Yongchuan [36] & $8,191.0$ & 6.0 & 36.6 & 43.1 & 9.9 & 3.9 \\
Jingning [37] & $3,711.0$ & 1.2 & 46.5 & 90.4 & 3.0 & 1.2 \\
Mean & $37,947.4$ & 28.4 & 63.9 & 41.7 & 4.8 & 2.0 \\
China[38] & $29,992.0$ & - & $133,972.0$ & 50.3 & 3.6 & 1.8 \\
\hline
\end{tabular}

${ }^{\mathrm{a}}$ Because of the similarities between Changshu and Liyang, the two counties are combined in this study. GDP, gross domestic product.

County from Sichuan; Yongchuan District from Chongqing and Jingning County from Gansu. To seek a balance of geographical and economic distribution between eastern China and western China, Liyang County from Jiangsu Province was added as the sample county. As a result, we selected five counties in China, whose basic characteristics in 2010, with comparisons to the national standard, are shown in Table 1. Changshu and Lilyang were in the developed eastern China; Mianzhu and Yongchuan were in the developing middle-east China, with a moderate level of economic development; and Jinning, from underdeveloped western China, was one of the Nationally Designated Poor Counties. Although considerations of the geographic distribution and socioeconomic status were taken in the sampling processes, we should acknowledge that the initial two steps of sampling were not random, and our choice of those counties was mainly based on the former collaboration between local health bureau and China Institute of Health.

The target population covered all village clinics and village doctors from the sample counties, while doctors who were not at practice were excluded. We obtained a list of all village clinics and village doctors in each county. As shown in Table 2, there were 1,271 village clinics (403 from Changshu and Liyang, 198 from Mianzhu, 270 from Yongchuan, and 400 from Jingning) and 2,250 village doctors (780 from Changshu and Liyang, 400 from Mianzhu, 700 from Yongchuan, and 370 from Jingning) listed in the table. All village doctors were asked to complete the Village Doctor Questionnaire, and village doctors who were the directors of village clinics were also asked to complete the Village Clinic Questionnaire.

\section{Data collection}

We sent ten interviewers to each county, including five professional investigators from the China Institute of Health and five employees from local health bureaus who were trained by experienced researchers for one week. The guidelines for investigators were created to illustrate the research objectives, explain each question, and standardize the interview procedure.

An informed consent form was given to each participant before the interview. If the respondents agreed to participate in the survey, then our interviewers gave a detailed explanation for the questions, supervised the entire survey process, and provided further introductions to interviewees when necessary. Interviewees who could not finish the questionnaire independently received help from project members. After the questionnaires were completed, the survey inspector examined the collected questionnaires; if the answers were incomplete or missed, a follow-up telephone interview was conducted. Overall, 78 questionnaires were redone by telephone interview.

\section{Data analysis}

Data entry was accomplished by Double Entry and Validation through EpiData 3.1 (The EpiData Association, Odense M, Denmark). Data analyses regarding the age, gender, education, practice methods, income, and anticipated pensions of village doctors were primarily descriptive, and correlation analyses were conducted to evaluate the relationship between education and practice methods. Statistical analyses were performed using Stata 12.0 (StataCorp LP, College Station, Texas, USA).

\section{Results}

The numbers and the response rates of village clinics and village doctors are presented in Table 2. Overall,

Table 2 The quantities and response rates of village clinics and village doctors

\begin{tabular}{lcccccc}
\hline County & \multicolumn{3}{c}{ Village clinics } & \multicolumn{3}{c}{ Village doctors } \\
\hline \multirow{2}{*}{ Changshu and Liyang } & $\mathbf{N}$ & $\mathbf{n}$ & $\%$ & $\mathbf{N}$ & $\mathbf{n}$ & $\%$ \\
Mianzhu & 403 & 303 & 75.2 & 780 & 659 & 84.5 \\
Yongchuan & 198 & 190 & 96.0 & 400 & 368 & 92.0 \\
Jingning & 270 & 253 & 93.7 & 700 & 604 & 86.3 \\
Total & 400 & 367 & 91.8 & 370 & 351 & 94.9 \\
\hline
\end{tabular}


Table 3 The gender and age distributions of village doctors

\begin{tabular}{lcccc}
\hline County & Male (\%) & Female (\%) & Male/Female & Mean age \\
\hline Changshu and Liyang & $428(64.9)$ & $231(35.1)$ & 1.9 & 56.4 \\
Mianzhu & $259(70.4)$ & $109(29.6)$ & 2.4 & 5.4 \\
Yongchuan & $491(81.3)$ & $113(18.7)$ & 4.4 & 48.3 \\
Jingning & $329(93.7)$ & $22(6.3)$ & 15.0 & 45.7 \\
Total & $1,507(76.0)$ & $475(24.0)$ & 3.2 & 51.3 \\
\hline
\end{tabular}

1,113 village clinics and 1,982 village doctors completed the questionnaires. The response rates were $87.6 \%$ and $88.1 \%$, respectively.

The gender and age distributions of the village doctors

The gender distributions and mean age of the village doctors in the surveyed counties are shown in Table 3. Of the 1,982 village doctors, 1,507 (76.0\%) were male, and $475(24.0 \%)$ were female. The gender distributions were different in different counties: 231 (35.1\%) females in Changshu and Liyang, 109 (29.6\%) in Mianzhu, 113 $(18.7 \%)$ in Yongchuan and $22(6.3 \%)$ in Jingning. Similarly, the male-to-female ratio was 1.9 in Changshu and Liyang, 2.4 in Mianzhu, 4.4 in Yongchuan, and 15.0 in Jingning, which showed the highest ratio.

The average age of all the interviewed village doctors was 51.3 years: 53.4 years in Changshu and Liyang, 52.5 years in Mianzhu, 48.3 years in Yongchuan, and 45.7 years in Jingning. It was found that age difference between Changshu and Liyang and Jingning was almost 10 years, indicating that the village doctors were much older in the relatively wealthier counties.

\section{Medical service practiced by village doctors}

In contrast to western countries, TCM has a long history in China and still plays an important role in the healthcare system. Hence, we asked the question: 'What kind of medicine do you practice: western medicine, TCM, or a mixture of western medicine and TCM?' to investigate the type of medicine practiced by the village doctors. Of the 1,982 respondents, 1,979 village doctors answered the question. As shown in Table 4, 761 (38.5\%)

Table 4 Practicing methods of village doctors

\begin{tabular}{lcccc}
\hline County & $\begin{array}{c}\text { Western } \\
\text { medicine } \\
(\%)\end{array}$ & $\begin{array}{c}\text { Traditional } \\
\text { Chinese } \\
\text { medicine (\%) }\end{array}$ & $\begin{array}{c}\text { Mixed } \\
\text { methods } \\
\text { (\%) }\end{array}$ & $\begin{array}{c}\text { Total } \\
(\%)\end{array}$ \\
\hline $\begin{array}{l}\text { Changshu } \\
\text { and Liyang }\end{array}$ & $294(44.6)$ & $4(0.6)$ & $361(54.8)$ & $659(100)$ \\
Mianzhu & $151(41.0)$ & $8(2.2)$ & $209(56.8)$ & $368(100)$ \\
Yongchuan & $251(41.8)$ & $34(5.7)$ & $316(52.6)$ & $601(100)$ \\
Jingning & $65(18.5)$ & $14(4.0)$ & $272(77.5)$ & $351(100)$ \\
Total & $761(38.5)$ & $60(3.0)$ & $1,158(58.5)$ & $1,979^{\mathrm{a}}(100)$ \\
\hline
\end{tabular}

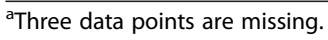

chose western medicine, only 60 (3.0\%) chose TCM, and 1,158 (58.5\%) chose mixed methods. In Changshu and Liyang, $44.6 \%$ of village doctors practiced western medicine. The ratios of western medicine doctors in Mianzhu and Yongchuan were similar (41.0\% versus $41.8 \%$ ). However, only 65 (18.5\%) village doctors in Jingning reported practicing western medicine.

\section{Village doctor education levels}

We also asked two questions to investigate the education levels of the village doctors: 'What is your highest education level: junior high school or less, high school, secondary school, junior college, and college or above?' and 'In what manner did you obtain your highest education level: prior to employment or as on-the-job training?'. Overall, the highest education level obtained by most village doctors (91.2\%) was secondary school (3 years' medical training after graduating from junior high school) or less. Only 5 of 1,982 village doctors obtained a college degree or higher. The education level in Jingning was slightly higher than the other counties, and the education levels in Changshu and Liyang were the lowest.

As shown in Table 5, 1,057 (57.1\%) village doctors reported that their highest education degrees were obtained after beginning working as a village doctor, while 793 (42.9\%) village doctors reported the opposite. This finding implied that more than half of the village doctors obtained their highest degree through on-the-job training.

Table 6 and Table 7 show the results of the correlation analyses of the relationship between the education and the practice method. The highest education degree was not correlated with the practice method $\left(\mathrm{X}^{2}=8.03, \mathrm{df}=8\right.$, $P=0.43)$. However, the way of obtaining the highest degree of education was closely related to the practice method $\left(x^{2}=34.14\right.$, df $\left.=2, P<0.01\right)$. Compared with village doctors who obtained their highest education degree by on-the-job training, those obtaining their highest degree before working as a doctor had a greater probability of practicing western medicine (46.3\% versus $33.0 \%$ ), a lower probability of practicing mixed methods $(64.0 \%$ versus $51.0 \%)$, and a similar probability of practicing TCM (3.0\% versus $2.7 \%)$. 
Table $\mathbf{5}$ The education level of village doctors

\begin{tabular}{|c|c|c|c|c|c|c|}
\hline County & $\begin{array}{l}\text { Junior high school } \\
\text { or less (\%) }\end{array}$ & High school (\%) & Secondary school (\%) & Junior college (\%) & $\begin{array}{l}\text { College or } \\
\text { above (\%) }\end{array}$ & Total (\%) \\
\hline Changshu and Liyang & $188(28.5)$ & $98(14.9)$ & $339(51.4)$ & $32(4.9)$ & $2(0.3)$ & $659(100)$ \\
\hline Mianzhu & $97(26.2)$ & $38(10.3)$ & $194(52.4)$ & $40(10.8)$ & $1(0.3)$ & $370(100)$ \\
\hline Yongchuan & $121(20.1)$ & $34(5.7)$ & $394(65.5)$ & $52(8.6)$ & $1(0.2)$ & $602(100)$ \\
\hline Jingning & $35(10.0)$ & $13(3.7)$ & $257(73.2)$ & $45(12.8)$ & $1(0.3)$ & $351(100)$ \\
\hline Total & $441(22.3)$ & $183(9.2)$ & $1,184(59.7)$ & $459(8.5)$ & $5(0.3)$ & $1,982(100)$ \\
\hline
\end{tabular}

\section{Village doctors' pensions and income}

Table 8 shows the basic income and pensions of the village doctors. The basic income was mainly the profits from medical services and did not include the public healthcare subsidy from the government or incomes from the agricultural activities of those village doctors who also had farmlands. The mean basic income was 1,817 RMB per month: 2,333 RMB in Changshu and Liyang, 1,958 RMB in Yongchuan, 1,019 RMB in Mianzhu, and 988 RMB in Jingning.

In Changshu and Yongchuan, 274 (83.3\%) doctors and 381 (66.8\%) doctors, respectively, had pensions. In contrast, only $8(2.3 \%)$ village doctors in Mianzhu, $9(3.2 \%)$ village doctors in Jingning and 85 (28.1\%) village doctors in Liyang had pensions. As a follow-up question, we asked: 'What is your expected pension per month after you retire?'. The self-reported pensions are shown in Table 5. Large gaps were observed between doctors from different counties. The expected pension was 2,051 RMB per month in Changshu and Liyang, 1,591 RMB per month in Mianzhu, 2,420 RMB per month in Yongchuan, and 1,177 RMB per month in Jingning.

\section{Discussion}

Due to the continuing expansion of the medical education in China [39], the aging of the healthcare workforce should not be a serious problem. In 2011, $68.3 \%$ of the licensed (assistant) doctors in hospitals and $73.0 \%$ of the licensed (assistant) doctors in the THCs were under 45 years of age; only $4.8 \%$ of the licensed (assistant) doctors in the hospitals and $3.2 \%$ of the licensed (assistant) doctors in the THCs were over 60 years of age according to the survey by the $\mathrm{MOH}$ [24]. However, among the village doctors in our sample, $41.3 \%$ were younger than 45 years old, and $30.0 \%$ were more than 60 years old, which was consistent with other studies [40,41]. The aging of the village doctors was partly due to the historical causes, as $45.3 \%$ of the village doctors were the barefoot doctors who started to work as a doctor before 1985, when the MOH began to use 'Village Doctor' to replace 'Barefoot Doctor' [16]. As shown above, there was no national pension for the village doctors, so they had to practice at the village clinics until reaching 60 years old or even after 60 years old to earn a living. Even worse, few young medical graduates supplemented the rural health workforce due to low salary and fewer opportunities etcetera. As a consequence, the percentage of aging village doctors has increased.

Furthermore, counties with greater economic development had a higher possibility of having older village doctors. As shown in Table 2, the village doctors in Changshu and Liyang were much older than those in Jingning. A potential explanation was that the young in Changshu and Liyang had better chances for making money, whereas practicing medicine in Jingning was not a bad option, which attracted more young people to join the healthcare workforce in the underdeveloped areas.

Unlike the aging problem that existed in all counties, the gender imbalance might only be a problem in poor counties. In Changshu, Liyang, Mianzhu, and Yongchuan, the gender imbalance was not a real problem because female village doctors composed one-third of all village doctors, while in Jingning, only $6.3 \%$ of the doctors were female $($ male/female $=15.0)$. That was troublesome because most of the public healthcare services (including maternal and gynecological care) were delivered by the

Table 6 The relationship between education and practicing methods

\begin{tabular}{|c|c|c|c|c|c|c|}
\hline \multirow[t]{2}{*}{ Practice methods } & \multicolumn{6}{|c|}{ Highest education degree } \\
\hline & $\begin{array}{c}\text { Junior high school } \\
\text { or less (\%) }\end{array}$ & High school (\%) & $\begin{array}{l}\text { Secondary } \\
\text { school (\%) }\end{array}$ & $\begin{array}{c}\text { Junior } \\
\text { college (\%) }\end{array}$ & $\begin{array}{l}\text { College or } \\
\text { above (\%) }\end{array}$ & Total (\%) \\
\hline Western medicine & 171(38.9) & $80(44.2)$ & $453(38.4)$ & $54(32.1)$ & $2(40.0)$ & $760(38.5)$ \\
\hline Traditional Chinese medicine & $9(2.1)$ & $5(2.8)$ & $40(3.4)$ & $4(2.4)$ & $0(0.0)$ & $58(2.9)$ \\
\hline Mixed methods & $260(59.1)$ & $96(53.0)$ & $687(58.2)$ & $110(65.5)$ & $3(60.0)$ & 1,156(58.6) \\
\hline Total & $440(100)$ & 181(100) & $1,180(100)$ & $168(100)$ & $5(100)$ & $1,974^{\mathrm{a}}(100)$ \\
\hline
\end{tabular}

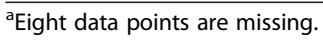


Table 7 The relationship between education and practicing methods of village doctors

\begin{tabular}{lccc}
\hline Practice methods & & When highest education degree is earned & \\
\cline { 2 - 4 } & On-the-job (\%) & Prior to employment (\%) & Total (\%) \\
\hline Western medicine & $347(33.0)$ & $366(46.3)$ & $713(38.7)$ \\
Traditional Chinese medicine & $32(3.0)$ & $21(2.7)$ & $53(2.9)$ \\
Mixed methods & $674(64.0)$ & $403(51.0)$ & $1,077(58.4)$ \\
Total & $1,053(100)$ & $790(100)$ & $1,843^{\mathrm{a}}(100)$ \\
\hline
\end{tabular}

${ }^{\mathrm{a}} 139$ data points are missing.

village doctors; unfortunately, customs often prevented women from seeking maternal and gynecological care from male village doctors [42].

In general, the western medicine, TCM and mixed methods were applied in all five counties, and mixed methods were the most frequently reported (58.5\%), followed by the western medicine (38.5\%) and TCM (3.0\%). However, the constitutions of the practice methods in the sampled counties differed from each other. The village doctors in Changshu and Liyang were more likely to practice western medicine (44.6\%), while the village doctors in Jingning preferred mixed methods (77.5\%). This might be due to the different purchasing power of the rural residents in different counties; the GDP per capita in Changshu can be as high as 96,518 $\mathrm{RMB}$, which is 26-fold greater than the 3,711 RMB GDP per capita in Jingning in 2010 [34,37]. The village doctors in Changshu could provide more expensive and profitable western medical services to the consumers, while the village doctors in Jingning preferred mixed methods, which included less expensive TCM.

Similar to the results of the national statistics of village doctors, only $5.3 \%$ of the village doctors obtained a degree from junior college or higher, and $75.6 \%$ had only completed a secondary school education [24]. The proportion of village doctors with a junior college degree or higher was much lower than that for licensed (assistant) doctors in hospitals (8.8\% versus $79.4 \%)$ and the licensed (assistant) doctors in THCs (8.8\% versus $51.5 \%)$ [24]. It might be difficult to meet the goals set by the central government, which requires that all village doctors to have at least a secondary school degree by the end of the year 2015 . Only $68.5 \%$ of village doctors had met that requirement in the year 2011.
We also found that the practice method was not correlated with the education level $(P=0.43)$, but closely related to the way of obtaining their highest education degree $(P<0.01)$. Most of the curricula in China's medical school were set for western medicine. Therefore, the village doctors who obtained their highest degree from medical school before beginning to work were more likely to practice western medicine, while the village doctors obtaining their highest degree through on-the-job training were more likely to practice mixed methods, as the mixed methods have been used to train the village doctors since the 1970s.

Good remuneration was regarded as a critical incentive for the recruitment and retention of healthcare workers in rural and remote areas [5,7,42-44], and it was also the major dynamic of the push-pull process of the domestic and international healthcare workforce migration $[45,46]$. The average annual income of the physicians in our study was 21,804 RMB in 2011, which was almost equal to the disposable income of the urban residents $(21,810 \mathrm{RMB})$ and three-fold greater than the net per capita income of the rural residents $(6,977 \mathrm{RMB})$ in 2011 [47]. If one takes the public health service bonus and other incomes from agriculture and other activities (for example, some village doctors have part-time jobs as couriers or drivers) into consideration, the total income for village doctors should be much higher than the income for common rural residents.

However, there are extremely large income gaps among village doctors in different districts. The highest income in our study was 40,000 RMB per month, while 74 village doctors earned less than $200 \mathrm{RMB}$ per month. Actually, village doctors in rural China acted as private practitioners [14] and competed with other village

Table 8 The income and pension of village doctors as RMB per month and percent

\begin{tabular}{|c|c|c|c|}
\hline County & Basic income $(95 \% \mathrm{Cl})$ & Doctors with pensions (\%) & Expected pensions $(95 \% \mathrm{Cl})$ \\
\hline Changshu and Liyang & $2,333(2,233$ to 2,432$)$ & $359(56.8)$ & $2,051(1,972$ to 2,131$)$ \\
\hline Mianzhu & $1,019(900$ to 1,139$)$ & $8(2.3)$ & $1,591(1,509$ to 1,672$)$ \\
\hline Yongchuan & $1,958(1,763$ to 2,152$)$ & $381(66.8)$ & $2,420(2,323$ to 2,516$)$ \\
\hline Jingning & 988 (808 to 1,168$)$ & $9(3.2)$ & $1,177(1,081$ to 1,272$)$ \\
\hline Total & $1,817(1,733$ to 1,900$)$ & $757(41.3)$ & $1,965(1,914$ to 2,015$)$ \\
\hline
\end{tabular}


doctors, private clinics and THCs after the collective economy collapsed, and their income was decided by the technique, relative advantages and local economic development. So it should not be surprising that huge income gaps exist among village doctors.

Being private practitioners rather than employees of the government, the village doctors could not enjoy the social protection provided by the government. In essence, the village doctors were treated almost the same as the farmers, although village doctors earned their living by providing medical services to rural residents. Rural residents in China lacked Social Pension Insurance before the State Council launched the New Rural Social Pension Insurance System (NRSPIS) in rural areas in 2009 [48]. Therefore, the village doctors, like the rural residents, could receive $55 \mathrm{RMB}$ per month, but they could not enjoy the additional pension provided by the government for their medical professional service at a national level. In this study, additional pensions were provided to the village doctors only in Changshu and Yongchuan, an effort intended to address the retirement of aging village doctors. Obviously, counties without additional pensions for older doctors might face these same challenges in the future, regardless of the local economic status.

This study, as a longitudinal study, might provide some fundamental knowledge on the current rural health workforce of China. However, a number of limitations of this study should be acknowledged. First, we did not test the validity or reliability of the questionnaires; however, the questionnaires were modified from the well-tested official ones, revised on the basis of focus group input, and their validity was improved with indepth interviews and pilot surveys. Additionally, not all village doctors participated in this survey, and missing values existed in the data collection. However, $88 \%$ was a relatively high response rate, and missing values were very small and randomized. Last, but not least, the generalization of the results should be conservative because it was not a random representative sample of the population.

In the next phase of this study, Hailun County from Heilongjiang Province (northeast China) will be added into this project and more detailed study about the aging, training, and public health services of village doctors will be conducted. Furthermore, physical and mental health conditions of village doctors will also be investigated by survey.

\section{Conclusions}

Gender imbalance of the village doctors, especially in the developed counties, was a serious problem that will be detrimental for the development of rural health. Therefore specific policy to recruit and retain female village doctors will be needed in the future. Low education levels of the village doctors, as a barrier to achieve the educational goals for the village doctors set by the government, should also be tackled through further onthe-job training or by recruiting more college medical graduates into the village clinics. The aging of the village doctors, together with the lack of pension for their professional service, has become an imperative issue, which is critical for the entrance and exit of the rural health workforce. This longitudinal study will track the inner structure of and dynamic evolution of the health workforce, which is meaningful for the development of the rural health workforce. Because health reform in China is still underway, both the positive and negative factors affecting health professionals are decisive to the outcome of the health reform. This longitudinal study will track the health workers' reactions to health reform, especially in regard to their desire that decision makers make a better and more suitable health reform scheme. In other words, this study will probably show the interplay between the health workforce and the ongoing health reform.

\section{Abbreviations}

GDP: Gross domestic product; MOH: Ministry of Health; TCM: Traditional Chinese Medicine; THCs: Township health centers.

\section{Competing interests}

The authors declare that they have no competing interests.

\section{Authors' contributions}

$\mathrm{DT}, \mathrm{XZ}, \mathrm{ZQ}, \mathrm{XW}, \mathrm{ZS}, \mathrm{HX}$ and WZ participated in the research design and project implementation. $\mathrm{HX}$ and $\mathrm{WZ}, \mathrm{YL}, \mathrm{SZ}, \mathrm{XQ}$, participated in the data collection and data analysis. HX and WZ wrote the original text. All of the authors read and approved the final manuscript.

\section{Acknowledgements}

This research was supported by the ' 985 ' platform project of Beijing Normal University, the Study on the Current Status and Developmental Trend of Village Doctors funded by the Ministry of Health of China and the Study on the Key Technologies of Rural Primary Healthcare funded by the Ministry of Science and Technology of China (Number: 2012BAJ18B00). We give many thanks to the employees of the health bureaus of the surveyed counties (Changshu, Liyang, Mianzhu, Yongchuan, and Jingning) for their meaningful work during the project. Thanks also to all the project participants.

Received: 14 July 2012 Accepted: 19 April 2013

Published: 4 May 2013

\section{References}

1. Chen Z: Launch of the health-care reform plan in China. Lancet 2009, 373:1322-1324.

2. Yip WC, Hsiao WC, Chen W, Hu S, Ma J, Maynard A: Early appraisal of China's huge and complex health-care reforms. Lancet 2012, 379:833-842.

3. Rigoli F, Dussault G: The interface between health sector reform and human resources in health. Hum Resour Health 2003, 1:9.

4. Anand S, Barnighausen T: Human resources and health outcomes: cross-country econometric study. Lancet 2004, 364:1603-1609.

5. Chen L, Evans T, Anand S, Boufford Jl, Brown H, Chowdhury M, Cueto M, Dare L, Dussault G, Elzinga G, Fee E, Habte D, Hanvoravongchai P, Jacobs M, Kurowski C, Michael S, Pablos-Mendez A, Sewankambo N, Solimano G, Stilwell B, de Waal A, Wibulpolprasert S: Human resources for health: overcoming the crisis. Lancet 2004, 364:1984-1990. 
6. Habte D, Dussault G, Dovlo D: Challenges confronting the health workforce in sub-Saharan Africa. World Hosp Health Serv 2004, 40:23-26. 40-21.

7. Hongoro C, McPake B: How to bridge the gap in human resources for health. Lancet 2004, 364:1451-1456.

8. Langmuir S: Barefoot doctors and health care in China. J Allied Health 1976, 5:9-13.

9. Wen C: Barefoot doctors in China. Nurs Dig 1975, 3:26-28.

10. Li VH: Politics and health care in China: the barefoot doctors. Stanford Law Rev 1975, 27:827-840.

11. Wen C: Barefoot Doctors in China. Lancet 1974, 303:976-978.

12. Daniels GL: China's barefoot doctors. J Med Soc N J 1974, 71:486-487.

13. Sidel WW: The barefoot doctors of the People's Republic of China. N Engl J Med 1972, 286:1292-1300.

14. Zhang D, Unschuld PU: China's barefoot doctor: past, present, and future. Lancet 2008, 372:1865-1867.

15. Maru RM: Health manpower strategies for rural health services in India and China: 1949-1975. Soc Sci Med 1977, 11:535-547.

16. Bing W, Youlong G, Xinping Z: The evolution of village doctors in China. Chinese Primary Health Care (in Chinese) 2000, 14:12-14.

17. Tang S, Meng Q, Chen L, Bekedam H, Evans T, Whitehead M: Tackling the challenges to health equity in China. Lancet 2008, 372:1493-1501.

18. Zhou $X$ : Economic transformation and income inequality in Urban China: evidence from panel data. Am J Socio/ 2000, 105:1135-1174.

19. Hesketh T, Wei XZ: Health in China. From Mao to market reform. BMJ 1997, 314:1543-1545.

20. Hsiao WC, Liu Y: Economic reform and health - lessons from China. N Eng J Med 1996, 335:430-432.

21. Hsiao WC: Transformation of health care in China. N Eng J Med 1984 310:932-936.

22. Blendon RJ: Can China's health care be transplanted without China's economic policies? N Eng J Med 1979, 300:1453-1458.

23. Youlong $G$, Wilkes $A$, Bloom $G$ : Health human resource development in rural China. Health Policy Plan 1997, 12:320-328.

24. Ministry of Health: 2012 China Health Statistics Yearbook (In Chinese). Beijing: Beijing Union Medical University Press; 2012

25. Smith AJ: Barefoot doctors and the medical pyramid. Br Med J 1974, 2:429-432.

26. Hsu RC: The Barefoot Doctors of the People's Republic of China - some problems. N Eng J Med 1974, 291:124-127.

27. Gong YL, Chao LM: The role of barefoot doctors. Am J Public Health 1982, 72:59-61.

28. Koplan JP, Hinman AR, Parker RL, Gong YL, Yang MD: The barefoot doctor: Shanghai County revisited. Am J Public Health 1985, 75:768-770.

29. Ronaghy HA, Solter S: Is the Chinese "barefoot doctor" exportable to rural Iran? Lancet 1974, 1:1331-1333.

30. Land T: China's 'barefoot doctors' to get medical training through new exchange program. Home Health J 1984, 5:19.

31. Rosenthal MM, Greiner JR: The Barefoot Doctors of China: from political creation to professionalization. Hum Organ 1982, 41:330-341.

32. Li X, Chongsuvivatwong V, Xia X, Sangsupawanich P, Zheng W, Ma K: Revisiting current "barefoot doctors" in border areas of China: system of services, financial issue and clinical practice prior to introducing integrated management of childhood illness (IMCI). BMC Publ Health 2012, 12:620.

33. Anand S, Fan VY, Zhang J, Zhang L, Ke Y, Dong Z, Chen LC: China's human resources for health: quantity, quality, and distribution. Lancet 2008, 372:1774-1781.

34. Jiangsu Provincial Bureau of Statistics: Jiangsu Statistics Yearbook 2011 (in Chinese). Beijing: China Statistics Press; 2011.

35. Sichuan Provincial Bureau of Statistics: Sichuan Statistics Yearbook 2011 (in Chinese). Beijing: China Statistics Press; 2011.

36. Chongqing Municipal Bureau of Statistics: Chongqing Statistics Yearbook 2011 (in Chinese). Beijing: China Statistics Press; 2011.

37. Gansu Provincial Bureau of Statistics: Gansu Development Statistics Yearbook 2011 (in Chinese). Beijing: China Statistics Press; 2011.

38. National Bureau of Statistics of China: China Statistics Yearbook 2011 (in Chinese). Beijing: China Statistics Press; 2011

39. Xu D, Sun B, Wan X, Ke Y: Reformation of medical education in China. Lancet 2010, 375:1502-1504.

40. Zhong Y, Wang Y, Cui X, Sun M, Li C, Wang H, Zhang W, Sun X, Chen Z, Hao M: Survey and analysis of village doctors from Shanghai. Chinese Primary Health Care (in Chinese) 2009, 23:7-10.
41. Zhen Q, Wang Z, Yan H: Survey and analysis of village doctors from 46 poor counties of 9 provinces in West China. China Journal Public Health (in Chinese) 2003, 19:175-176.

42. Zurn P, Dal Poz MR, Stilwell B, Adams O: Imbalance in the health workforce. Hum Resour Health 2004, 2:13.

43. Cayley W Jr: Continuing challenges to adequate health care workforce in sub-Saharan Africa. Fam Med 2009, 41:595-596.

44. Beaglehole R, Sanders D, Dal Poz M: The public health workforce in subSaharan Africa: challenges and opportunities. Ethn Dis 2003, 13:S24-S30.

45. Kanchanachitra C, Lindelow M, Johnston T, Hanvoravongchai P, Lorenzo FM, Huong NL, Wilopo SA, Dela Rosa JF: Human resources for health in southeast Asia: shortages, distributional challenges, and international trade in health services. Lancet 2011, 377:769-781.

46. Kuehn BM: Global shortage of health workers, brain drain stress developing countries. JAMA 2007, 298:1853-1855.

47. National Bureau of Statistics of China: Statistical Communiqué of the People's Republic of China on the 2011 National Economic and Social Development (in Chinese). http://www.stats.gov.cn/tjgb/ndtjgb/qgndtjgb/ t20120222_402786440.htm.

48. State Council: The Guidance of the State Council to Launch the New Rural Social Pension Insurance System (in Chinese). http://www.gov.cn/zwgk/200909/04/content_1409216.htm.

doi:10.1186/1478-4491-11-17

Cite this article as: Xu et al.: Longitudinal study of rural health workforce in five counties in China: research design and baseline description. Human Resources for Health 2013 11:17.

\section{Submit your next manuscript to BioMed Central and take full advantage of:}

- Convenient online submission

- Thorough peer review

- No space constraints or color figure charges

- Immediate publication on acceptance

- Inclusion in PubMed, CAS, Scopus and Google Scholar

- Research which is freely available for redistribution

Submit your manuscript at www.biomedcentral.com/submit
C) Biomed Central 